OPEN ACCESS

Edited by:

Gislane Lelis Vilela de Oliveira,

São Paulo State University, Brazil

Reviewed by:

António Machado,

Universidad San Francisco de Quito,

Ecuador

Andrew Maltez Thomas,

University of Trento, Italy

${ }^{*}$ Correspondence: Ninfa Ramírez-Durán ninfard@hotmail.com

Specialty section:

This article was submitted to Microbiome in Health and Disease, a section of the journal

Frontiers in Cellular and Infection Microbiology

Received: 17 December 2021 Accepted: 13 January 2022

Published: 02 February 2022

Citation: Manzanares-Leal GL, Coronel-Martínez JA, Rodríguez-Morales $M$ Rangel-Cuevas I, Bustamante-Montes LP,

Sandoval-Truillo $H$ and Ramírez-Durán N (2022)

Preliminary Identification of the Aerobic Cervicovaginal

Microbiota in Mexican Women With Cervical Cancer as the First Step Towards Metagenomic Studies. Front. Cell. Infect. Microbiol. 12:838491. doi: 10.3389/fcimb.2022.838491

\section{Preliminary Identification of the Aerobic Cervicovaginal Microbiota in Mexican Women With Cervical Cancer as the First Step Towards Metagenomic Studies}

\author{
Gauddy Lizeth Manzanares-Leal ${ }^{1}$, Jaime Alberto Coronel-Martínez ${ }^{2}$, \\ Miguel Rodríguez-Morales ${ }^{3}$, Iván Rangel-Cuevas ${ }^{4}$, Lilia Patricia Bustamante-Montes ${ }^{5}$, \\ Horacio Sandoval-Trujillo ${ }^{6}$ and Ninfa Ramírez-Durán ${ }^{1 *}$
}

\begin{abstract}
${ }^{1}$ Laboratory of Medical and Environmental Microbiology, School of Medicine, Universidad Autonoma del Estado de Mexico, Toluca, Mexico, 2 Departments of Clinical Research and Medical Oncology, Instituto Nacional de Cancerologia, Mexico City, Mexico, ${ }^{3}$ Genomics Laboratory, Instituto Nacional de Cancerologia, Mexico City, Mexico, ${ }^{4}$ Gynecology Department, Maternal and Child Hospital, Instituto de Seguridad Social del Estado de México y Municipios, Toluca, Mexico, ${ }^{5}$ Deanship of Health Sciences, Universidad Autonoma de Guadalajara, Guadalajara, Jalisco, Mexico, ${ }^{6}$ Department of Biological Systems, Universidad Autonoma Metropolitana-Xochimilco, Mexico City, Mexico
\end{abstract}

Cervical cancer (CC) is considered a public health problem. Recent studies have evaluated the possible relationship between the cervicovaginal microbiome and gynecologic cancer but have not studied the relationship between aerobic bacterial communities and neoplasia. The study aimed to identify the cultivable aerobic bacterial microbiota in women with cervical cancer as a preliminary approach to the metagenomic study of the cervicovaginal microbiome associated with cervical cancer in Mexican women. An observational crosssectional study was conducted, including 120 women aged 21-71 years, divided into two study groups, women with locally advanced CC ( $n=60)$ and women without CC ( $n=60)$. Sociodemographic, gynecological-obstetric, sexual, and habit data were collected. Cervicovaginal samples were collected by swabbing, from which standard microbiological methods obtained culturable bacteria. The strains were genetically characterized by PCR-RFLP of the 16S $r$ RNA gene and subsequently identified by sequencing the same gene. Variables regularly reported as risk factors for the disease were found in women with CC. Differences were found in the prevalence and number of species isolated in each study group. Bacteria commonly reported in women with aerobic vaginitis were identified. There were 12 species in women with CC, mainly Corynebacterium spp. and Staphylococcus spp.; we found 13 bacterial species in the group without cancer, mainly Enterococcus spp. and Escherichia spp. The advanced stages presented a more significant number of isolates and species. This study provided a preliminary test for cervicovaginal metagenomic analysis, demonstrating the presence of aerobic cervicovaginal dysbiosis in women with CC and the need for more in-depth studies. 


\section{INTRODUCTION}

Cervical cancer (CC) is one of the significant public health problems in the world. Globally, it represents the seventh most common cancer in humans and the fourth most common cancer in women, but it reaches second place in incidence and mortality in settings with a low human development index (Bray et al., 2018). In Mexico, this condition is aggravated because the diagnosis mainly occurs in locally advanced stages (IB-2 to IV-A), placing the pathology as the second leading cause of cancer death in women (Baezconde-Garbanati et al., 2019; Martínez-Rodríguez et al., 2021).

Recent studies have evaluated the relationship between the cervicovaginal microbiome and gynecological cancer to elucidate the involvement of bacterial communities in the establishment, progression, or cure of the disease. Dysbiosis due to the presence of bacterial vaginosis is the most studied entity, found to have a possible association with the induction of local inflammation and lactic acid depletion (Anahtar et al., 2015; Łaniewski et al., 2018), persistent high-risk Human Papillomavirus (HPV-Hr) infection (Jørgensen et al., 2009; Gao et al., 2013; Piyathilake et al., 2016; Ilhan et al., 2019; Norenhag et al., 2020; Wei et al., 2020), Cervical Intraepithelial Neoplasia (CIN) (Gillet et al., 2012; Huang et al., 2020) and the establishment of cervical cancer (Kwasniewski et al., 2018; Huang et al., 2020; Kang et al., 2021).

Among the main bacterial genera reported so far concerning CC are Gardnerella, Prevotella, Dialister, Slackia, Actinomyces, Porphyromonas, Peptoniphilus, Anaerococcus, Peptostreptococcus, Streptococcus, Ureaplasma, Megasphaera, Mycoplasma, Sneathia, Mobiluncus, Fusobacterium, and Atopobium (Anahtar et al., 2015; Di Paola et al., 2017; Wei et al., 2020), all of which are facultative anaerobic or strict anaerobic bacteria.

In 2002, Donders et al. (2002) reported the existence of a pathological entity called aerobic vaginitis, characterized by a high abundance and diversity of aerobic, enteric bacteria and inflammatory symptoms. In 2019, Wang et al. (2020) evaluated the bacterial profiles of aerobic vaginitis by both culturedependent and molecular methods. They found no single profile to describe the vaginal bacteriome in patients with aerobic vaginitis. In 2021, Plisko et al. (2021) published a paper whose objective was to analyze the association between the vaginal microbiota of women with aerobic vaginitis and the presence of cervical intraepithelial neoplasia. In this study, aerobic microbiota was detected by wet-mount microscopy. The authors concluded that there might be a relationship between aerobic dysbiotic cervicovaginal microbiota and the development of cervical intraepithelial lesions.

Currently, to our knowledge, the aerobic microbiota present in women with established cervical cancer has not been evaluated. Therefore, this study aimed to identify the culturable aerobic bacterial microbiota in women with locally advanced cervical cancer as an approach before the metagenomic study of the cervicovaginal microbiome associated with cervical cancer in Mexican women.

\section{METHOD}

\section{Study Design and Ethical Aspects}

A cross-sectional, descriptive, observational study was carried out. Cervicovaginal fluid samples were collected by swabbing. Sample collection was developed from February 2016 to February 2018. The study protocol was approved by the National Cancer Institute of Mexico (INCan) with the code 016/11/ICI-ICI-CEI/1016. All procedures were carried out under proper bioethical standards. All women who decided to participate in the study signed the corresponding informed consent form.

\section{Study Groups}

Two study groups were included, according to the following characteristics: Study group 1 (CC): women older than 18 years, newly diagnosed with locally advanced cervical cancer, according to the International Federation of Gynecology and Obstetrics (FIGO) staging system for cervical cancer (Saleh et al., 2020), and histologically confirmed $(\mathrm{n}=60)$; Study group 2 (Non-CC): women older than 18 years, without cervical cancer, confirmed with negative cervical cytology, companions (family members or neighbors) of women in study group 1 or who attended screening appointments $(\mathrm{n}=60)$.

The following exclusion criteria were applied: pregnant women, women who used systemic and local antimicrobials and antifungals 30 days before sampling, women who had sexual intercourse 48 hours before sampling, women who used vaginal douching, and who were menstruating on the day of sampling.

\section{Study Population Characteristics}

A questionnaire was applied to all participants to obtain sociodemographic data (age, education level, and marital status); gynecological-obstetric data (number of vaginal deliveries); sexual data (start of active sexual life, number of sexual partners, and use of hormonal contraceptive methods); habits (smoking); and disease data collected from clinical histories (clinical stage of the disease, histological type of tumor).

\section{Sample Processing}

Cervicovaginal fluid samples were inoculated in Petri dishes with Brain Heart Infusion (BHI) agar (Becton Dickinson, Cat. No. 214700) and in Petri dishes with blood agar (Becton Dickinson, Cat. No. 220150). The Petri dishes were incubated at $37^{\circ} \mathrm{C}$ for 48 $\mathrm{hr}$ under aerobic conditions. Once the incubation time had elapsed, the predominant colonies were isolated and purified.

\section{DNA Extraction}

The isolated and purified colonies were inoculated in BHI broth to obtain biomass, incubated at $37^{\circ} \mathrm{C}$ for $48 \mathrm{hr}$. Biomass recovery was performed by centrifugation at $10000 \mathrm{rpm}$ for 10 minutes. Subsequently, the manufacturer's instructions performed DNA extraction using the Promega Wizard ${ }^{\circledR}$ Genomic kit (Cat. No. A1120). 


\section{Amplification of the 16S rRNA Gene}

The 16S $r$ RNA gene was amplified with the DNA obtained by Polymerase Chain Reaction (PCR). Taq DNA Polymerase (My Taq, Bioline. Cat. No. BIO-21105) was used and the following nucleotide sequences were used as universal primers: 27f: 5'AGAGTTTGATCMTGGCTCAG-3'; 1492r: 5'- TACGGYTACC TTGTTACGACTT-3'; 1492r: 5'- TACGGYTACCTTGTTA CGACTT-3'. The conditions used in thermal cycling for gene amplification were as follows: Initial denaturation, a 5-minute cycle at $94^{\circ} \mathrm{C}$, followed by 29 cycles of denaturation for 1 minute at $94^{\circ} \mathrm{C}$, annealing 30 seconds at $59^{\circ} \mathrm{C}$, extension 1 minute at $72^{\circ} \mathrm{C}$. The final extension was 10 minutes at $72^{\circ} \mathrm{C}$.

The amplified fragments were observed by $1 \%$ agarose gel electrophoresis (Conda Pronadisa, cat. no. 8100.10), stained with ethidium bromide (SIGMA cat. no. E7637-1G). The electrophoresis conditions were: $120 \mathrm{~V}$ for $40 \mathrm{~min}$, in TAE buffer (TAE buffer 1X Invitrogen, Cat. No. 24710-030) as a running buffer.

\section{Genomic Characterization}

The amplicons of the 16S $r$ RNA gene of the isolated strains were used to type the strains obtained to determine the genotypic differences of the isolates. For this purpose, PCR-RFLP ribotyping of the 16S $r$ RNA gene with MSPI (Promega, Cat. No. R6401) and RSAI (Promega, Cat. No. R6371) enzymes were used. For both enzymes, the restriction reaction was carried out for $1 \mathrm{~h}$ at $37^{\circ} \mathrm{C}$, inactivated by heating $15 \mathrm{~min}$ at $72^{\circ} \mathrm{C}$, according to the manufacturer's instructions.

Restriction products were observed by $1.5 \%$ agarose gel electrophoresis (Conda Pronadisa, Cat. No. 8100.10), stained with ethidium bromide (SIGMA Cat. No. E7637-1G), under the following conditions: $120 \mathrm{~V}$ for 80 minutes with TAE buffer (TAE buffer 1X Invitrogen, Cat. No. 24710-030) and $1 \mathrm{~kb}$ DNA molecular weight marker (Thermo Scientific, Cat. No. 5M0311).

The restriction patterns generated were analyzed according to the number of bands and size concerning the molecular weight marker used. A "ribotype" was defined as a group of strains with identical enzymatic restriction profiles

\section{Genetic Identification}

For genetic identification, between $15 \%$ and $50 \%$ of the strains from the ribotypes formed were selected. Once the representative strains were chosen, a second amplification of the 16S $r$ RNA gene was performed by PCR, following the methodology described above. The amplification products were purified with the Amicon Ultra filter ${ }^{\circledR}$ kit (Millipore, Cat. No. UFC500308) and sent to the Macrogen USA sequencing service (Macrogen Sequenciation Service, Maryland, USA).

The sequences were analyzed and corrected with the following programs: ChromasPro version 2.6.4 (Technelysium Pty Ltd, South Brisbane, Australia) and BioEdit version 5.0.9 (Hall, 1999). Consensus sequences were constructed and compared with sequences deposited in the GenBank of the National Center for Biotechnology Information (NCBI) using the BLAST (Basic Local Alignment Search Tool) program
(Altschul et al., 1990) as well as in the EzBiocloud public database (Yoon et al., 2017).

\section{Statistical Analysis}

Sociodemographic, gynecological-obstetric, sexual, habit, and disease characteristics and the number of isolated strains were analyzed using descriptive statistics. The Student's t-test compared the mean age of the participants. The Chi 2 test was used to compare the proportions of the remaining variables and the number of isolates per culture medium. The CochranMantel-Haenszel test was applied to rule out the possibility of sociodemographic variables acting as confounding variables in the presence or absence of isolated bacteria. For women with CC, analysis of the proportion of strains obtained by subgroup, stratified by parametrial and non-parametrial invasion, and tumor type was performed using Fisher's exact test. A significance level of $\mathrm{p}<0.05$ was considered. Stata version 15 was used for the analysis of all data evaluated.

\section{RESULTS}

\section{Sociodemographic, Gyneco-Obstetric, Sexual, and Habit Characteristics}

Regarding the characteristics of the study population, the groups did not differ in age. Still, statistically significant differences were found in the level of education $(\mathrm{p}=0.01)$, vaginal deliveries $(\mathrm{p}<0.01)$, beginning of active sexual life $(\mathrm{p}<0.01)$, and use of contraceptive methods $(\mathrm{p}=0.02)$ (Table 1). For the women with $\mathrm{CC}$, the clinical stage of the disease most frequently was IIB (50\%), and squamous cell carcinoma accounted for $85 \%$ of the cases (Table 1). Statistically, no variable in this item acted as a confounder.

\section{Strains Isolated}

From study group 1 (CC), 116 strains were isolated; 52 on BHI agar $(44.8 \%)$ and 64 on blood agar (55.2\%). In group 2 (NonCC), 67 strains were isolated; 21 on $\mathrm{BHI}$ agar (31.3\%) and 46 on blood agar (68.7\%). It can be observed that the group of women with CC presented a superior number of isolated strains; however, when comparing the proportions by type of culture medium, this result was not statistically significant $(\mathrm{p}=0.07)$.

\section{Genomic Characterization}

The 16S rRNA gene of the isolated strains was characterized using restriction enzymes. The gene fragments generated by the enzymes could be visualized and adequately separated by agarose gel electrophoresis; this generated bands that varied in number, size, and arrangement, which showed that the strains were genetically distinct and allowed their classification by grouping patterns of similar bands or ribotypes. Thus, 12 ribotypes were found in the group of women with CC, and 13 ribotypes were found in Study Group 2 (Non-CC) (Table 2). Using two restriction enzymes (MSPI and RSAI), we corroborated that the strains clustered as described, and the groups were genetically distinct. 
TABLE 1 | Characteristics of the study population.

\begin{tabular}{|c|c|c|c|}
\hline Characteristic & Study group 1 (CC) $(n=60)$ & Study group 2 (Non-CC) $(n=60)$ & Significance \\
\hline \multicolumn{4}{|c|}{ Sociodemographic characteristics } \\
\hline \multirow[t]{2}{*}{ Age } & Mean (range, S.D.) & Mean (range, S.D.) & \\
\hline & $46(22-68,11.9)$ & $45(21-71,11.7)$ & 0.57 \\
\hline Education level & Frequency (\%) & Frequency (\%) & \\
\hline None & $12(20.0)$ & $5(8.3)$ & $0.01^{\star}$ \\
\hline Elementary & $20(33.3)$ & $13(21.6)$ & \\
\hline Secondary & 19 (31.6) & $19(31.6)$ & \\
\hline High school & $8(13.3)$ & $15(25.0)$ & \\
\hline University and postgraduate & $3(5.0)$ & $8(13.3)$ & \\
\hline \multicolumn{4}{|l|}{ Marital Status } \\
\hline Married/free union & $31(51.6)$ & $36(60.0)$ & 0.16 \\
\hline Widowed & $6(10.0)$ & $3(5.0)$ & \\
\hline \multirow[t]{2}{*}{ Single } & $23(38.3)$ & $21(35.0)$ & \\
\hline & \multicolumn{2}{|c|}{ Obstetrical and gynecological characteristics } & \\
\hline Deliveries & Frequency (\%) & Frequency (\%) & \\
\hline$\leq 3$ & 38 (63.3) & $56(93.3)$ & $<0.01^{*}$ \\
\hline \multirow[t]{2}{*}{$>3$} & $22(36.6)$ & $4(6.6)$ & \\
\hline & \multicolumn{2}{|c|}{ Sexual characteristics } & \\
\hline Beginning of active sexual life & Frequency (\%) & Frequency (\%) & \\
\hline$\leq 18$ years & $38(63.3)$ & $27(45.0)$ & $<0.01^{\star}$ \\
\hline$>18$ years & $22(36.6)$ & $33(55.0)$ & \\
\hline \multicolumn{4}{|l|}{ Number of sexual partners } \\
\hline$\leq 3$ & $53(88.3)$ & 49 (81.6) & 0.44 \\
\hline$>3$ & 7 (11.6) & $11(18.3)$ & \\
\hline \multicolumn{4}{|l|}{ Contraceptive method use } \\
\hline None & $31(51.6)$ & $28(46.6)$ & $0.02^{\star}$ \\
\hline Hormonal & 19 (31.6) & $10(16.6)$ & \\
\hline \multirow[t]{2}{*}{ Non- hormonal } & $10(16.6)$ & $22(36.6)$ & \\
\hline & \multicolumn{2}{|c|}{ Habits } & \\
\hline Smoking habit & Frequency (\%) & Frequency (\%) & \\
\hline Yes & $11(18.3)$ & $18(30.0)$ & 0.66 \\
\hline \multirow[t]{2}{*}{ No } & $49(81.6)$ & $42(70.0)$ & \\
\hline & \multicolumn{2}{|c|}{ Disease } & \\
\hline Clinical stage & Frequency (\%) & Frequency (\%) & \\
\hline IB2 & $9(15.0)$ & $\mathrm{N} / \mathrm{A}$ & $\mathrm{N} / \mathrm{A}$ \\
\hline$\| \mathrm{A}$ & $3(5.0)$ & N/A & $\mathrm{N} / \mathrm{A}$ \\
\hline$\| \mathrm{A} 1$ & $1(1.6)$ & N/A & $\mathrm{N} / \mathrm{A}$ \\
\hline$\| \mathrm{A} 2$ & $2(3.3)$ & N/A & $\mathrm{N} / \mathrm{A}$ \\
\hline IIB & $30(50.0)$ & N/A & $\mathrm{N} / \mathrm{A}$ \\
\hline$\| \mathrm{A}$ & $2(3.3)$ & N/A & N/A \\
\hline IIIB & 8 (13.3) & $\mathrm{N} / \mathrm{A}$ & $\mathrm{N} / \mathrm{A}$ \\
\hline IVA & $5(8.3)$ & N/A & $\mathrm{N} / \mathrm{A}$ \\
\hline \multicolumn{4}{|l|}{ Tumor histological type } \\
\hline Squamous cell carcinoma & $51(85.0)$ & N/A & $\mathrm{N} / \mathrm{A}$ \\
\hline Adenocarcinoma & $9(15.0)$ & N/A & $\mathrm{N} / \mathrm{A}$ \\
\hline
\end{tabular}

S.D, Standard deviation, \%, percentage, N/A, not applicable. *Significance level $p<0.05$, Student's t-test or chi2 test.

\section{Genetic Identification}

Identification by $16 \mathrm{~S} r \mathrm{RNA}$ gene sequencing was performed on 40 strains representative of the 12 ribotypes of study group 1 (CC). Consensus sequences between $1311 \mathrm{bp}$ and $1472 \mathrm{bp}$ were obtained, with similarity percentages between $97 \%$ and $100 \%$. Seven genera and 12 bacterial species were identified. The species corresponded to each of the ribotypes established in this study group (Table 2).

From Study Group 2 (Non-CC), 30 strains of 13 ribotypes were chosen. Consensus sequences between 1391bp and 1436bp were obtained with $97 \%$ and $100 \%$ similarity percentages. 10 genera and 13 bacterial species were identified. The species correspond to the ribotypes established in this group (Table 2).
The obtained sequences were deposited in the GenBank of the National Center for Biotechnology Information with access numbers MH108987-MH109026 (Group 1) and MH158254MH158283 (Group 2).

Both women with CC and those without the disease presented mostly facultative aerobic and enteric bacteria. Staphylococcus epidermidis, Streptococcus agalactiae, Enterococcus faecalis, Escherichia fergusonii, and Corynebacterium amycolatum species were identified in both study groups, with percentages between $5 \%$ and $30 \%$ of presence in the group of women with CC and between $6 \%$ and $25 \%$ in women without CC.

The women with CC presented a specific bacterial community, which could not be isolated in women without 


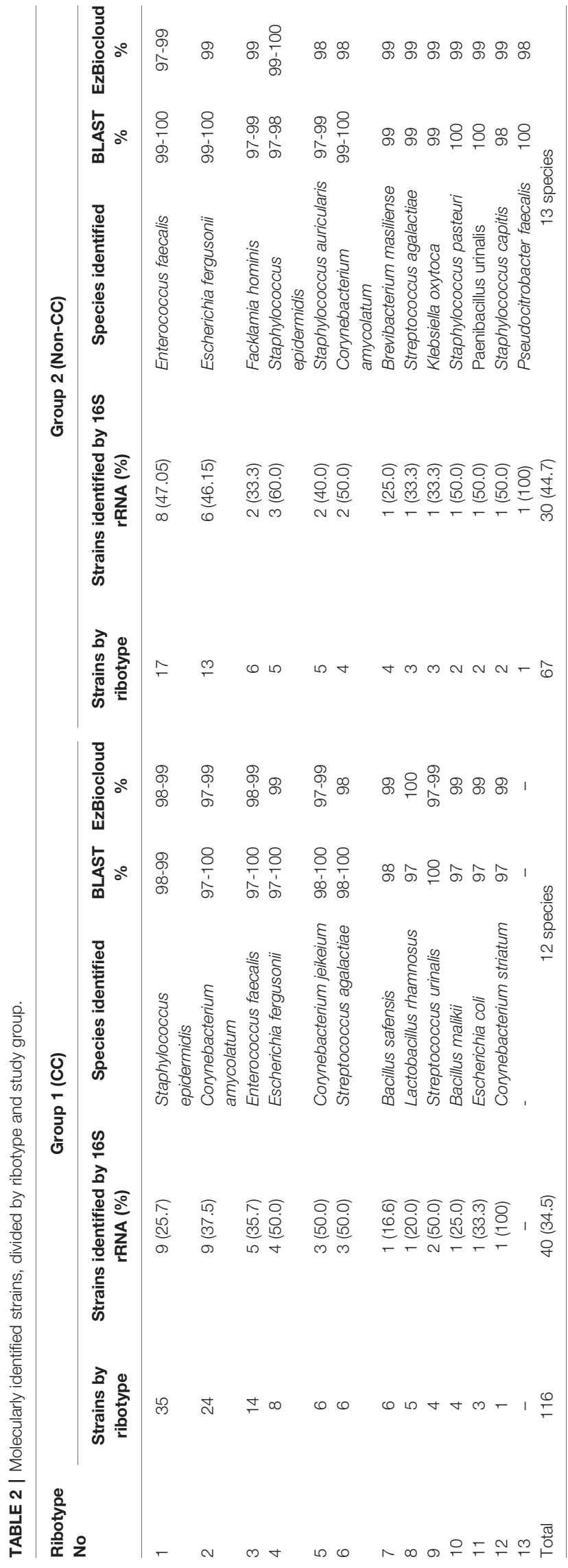

CC, consisting of seven species, Streptococcus urinalis, Escherichia coli, Bacillus safensis, Bacillus malikii, Corynebacterium jeikeium, Corynebacterium striatum, and Lactobacillus rhamnosus. Likewise, the group of women without CC presented eight species not found in those with CC, consisting of Staphylococcus pasteuri, Staphylococcus auricularis, Staphylococcus capitis subsp. capitis, Facklamia hominis, Paenibacillus urinalis, Pseudocitrobacter faecalis, Brevibacterium masiliense and Klebsiella oxytoca.

Clinical stages of the disease were divided for analysis according to the presence or absence of parametrial invasion. Stages IB2 to IIA2 (without parametrial invasion) presented 8 bacterial species. The women with parametrial invasion (stages IIB to IVA) presented the 12 species identified. The species with the highest predominance was Staphylococcus epidermidis, as it was present in $100 \%$ of the patients without parametrial invasion, compared to $44.4 \%$ found in women with parametrial invasion; this result is statistically significant $(\mathrm{p}<0.01)$ (Table 3).

Regarding the species found according to the histological type of tumor, women with squamous cell carcinoma presented 11 of the 12 species identified (91.6\%), except for Corynebacterium striatum. Women with adenocarcinoma presented 9 of the 12 species $(75 \%)$. The difference in proportions between both groups for all bacteria only showed statistically significant differences in the presence of $C$. amycolatum $(\mathrm{p}<0.01)$, with a higher proportion in women with adenocarcinoma (Table 3).

\section{DISCUSSION}

Cervical cancer is one of the leading health problems in the world; there are multiple reports about the risk factors associated with HPV infection, its persistence, and cancer development. We have detected four risk factors in the Mexican population analyzed in this study. Education level, which can be related to socioeconomic status, was lower in the group of women with cervical cancer, coinciding with previous studies showing that detection of the disease is later as schooling level decreases (Chen et al., 2012; Thulaseedharan et al., 2012; Akinlotan et al., 2017; Nessa et al., 2020). The onset of active sexual life was at an earlier age in women with CC, and it has been reported that early age at first intercourse may predispose women to HPV infection (Creatsas and Deligeoroglou, 2012; Dahiya et al., 2017). Parity, which was higher in women with CC. This risk factor may be related to hormonal changes and epithelial modifications caused by repeated cervical trauma (Thulaseedharan et al., 2012; Nessa et al., 2020). And finally, the use of contraceptive methods, in which the higher use of hormonal methods by women with CC is observed.

It has been commonly reported that the composition of "healthy" or "normal" cervicovaginal bacterial communities is based on the presence or absence of lactobacilli. Ravel et al. (2011) have classified it into multiple categories or "clusters" (I-V) based on the dominant Lactobacillus species and the ethnic group in which they are found. Bacterial 
TABLE 3 | Difference in proportions of bacterial species found according to the clinical stage of the disease and histological type of tumor.

\begin{tabular}{|c|c|c|c|c|c|c|}
\hline \multirow[t]{2}{*}{ Identified species } & \multicolumn{2}{|c|}{ Clinical stage } & \multirow[t]{2}{*}{ Significance } & \multicolumn{2}{|c|}{ Tumor histological type } & \multirow[t]{2}{*}{ Significance } \\
\hline & $\begin{array}{l}\text { IB2, IIA, IIA1, IIA2 (Without } \\
\text { parametrial invasion) } n=15\end{array}$ & $\begin{array}{c}\text { IIB, IIIA, IIIB, IVA (With } \\
\text { parametrial invasion) } \\
n=45\end{array}$ & & $\begin{array}{l}\text { Squamous cell } \\
\text { carcinoma }=51\end{array}$ & $\begin{array}{l}\text { Adenocarcinoma } \\
\qquad \mathrm{n}=9\end{array}$ & \\
\hline & \% (Frequency) & \% (Frequency) & & \% (Frequency) & \% (Frequency) & \\
\hline Staphylococcus epidermidis & $100(15)$ & $44.4(20)$ & $<0.01^{\star}$ & $56.8(29)$ & $66.6(6)$ & 0.72 \\
\hline Corynebacterium amycolatum & $40.0(6)$ & $40.0(18)$ & 1.00 & $31.3(16)$ & $88.8(8)$ & $<0.01^{\star}$ \\
\hline Enterococcus faecalis & $26.0(4)$ & $22.2(10)$ & 0.73 & $21.5(11)$ & $33.3(3)$ & 0.18 \\
\hline Escherichia fergusonii & $6.6(1)$ & $15.5(7)$ & 0.66 & $15.6(8)$ & $0.0(0)$ & 0.33 \\
\hline Corynebacterium jeikeium & $6.6(1)$ & $11.1(5)$ & 1.00 & $11.7(6)$ & $0.0(0)$ & 0.57 \\
\hline Streptococcus agalactiae & $0.0(0)$ & $13.3(6)$ & 0.32 & $9.8(5)$ & $11.1(1)$ & 1.00 \\
\hline Bacillus safensis & $13.3(2)$ & $8.8(4)$ & 0.63 & $9.8(5)$ & $0.0(0)$ & 1.00 \\
\hline Lactobacillus rhamnosus & $13.3(2)$ & $6.6(3)$ & 0.59 & $7.8(4)$ & $11.1(1)$ & 0.57 \\
\hline Streptococcus urinalis & $0.0(0)$ & $8.8(4)$ & 0.56 & $3.9(2)$ & $11.1(1)$ & 0.39 \\
\hline Bacillus malikii & $6.6(1)$ & $6.6(3)$ & 1.00 & $3.9(2)$ & $22.2(2)$ & 0.10 \\
\hline Escherichia coli & $0.0(0)$ & $6.6(3)$ & 0.56 & $3.9(2)$ & $11.1(1)$ & 0.39 \\
\hline Corynebacterium striatum & $0.0(0)$ & $2.2(1)$ & 1.00 & $0.0(0)$ & $11.1(1)$ & 0.15 \\
\hline
\end{tabular}

$\%$, percentage; *significance level $p<0.05$, Fisher's exact test.

communities I, II III and V, are dominated by Lactobacillus crispatus, L. gasseri, L. iners, and L. jensenii, respectively, and were found more frequently in Asian and white women. Bacterial community IV is not dominated by any lactobacillus species and has a high presence of anaerobic bacteria. This group was overrepresented in Hispanic and black women, concluding that vaginal bacterial communities not dominated by Lactobacillus species are common and appear normal in these ethnic groups (Ravel et al., 2011; Kroon et al., 2018). However, according to Martínez-Peña et al. (Martínez-Peña et al., 2013), the healthy cervicovaginal microbiota of Mexican women is mainly composed of $L$. acidophilus group lactobacilli, namely $L$. gasseri, L. fermentum, L. rhamnosus, L. jensenii, L. crispatus and $L$. brevis, which is in contrast to that described by Ravel et al. (Ravel et al., 2011). Likewise, our results also show the presence of critical aerobic bacteria in women without CC. We believe that further studies are needed to establish the normal parameters of this bacterial community and to determine with greater certainty the variation according to population, genotype, or the presence of disease.

Several studies have already exposed the link of cervicovaginal bacterial microbiota and CC during the natural history of the disease, where it is shown that from HPV infection and up to the presence of a cervical intraepithelial lesion, there is an association between cervical dysbiosis and disease (Mitra et al., 2015; Usyk et al., 2020; Onywera et al., 2021). The most studied entity is bacterial vaginosis, in which a higher diversity of strict anaerobic species and a considerable decrease in lactobacilli are observed (Sodhani et al., 2017; Brusselaers et al., 2019; Kovachev, 2020). However, current reports suggest that aerobic bacteria may also play an essential role in this pathology (Vieira-Baptista et al., 2016; Plisko et al., 2021).

This study aimed to detect aerobic bacteria related to the presence of CC. Our findings show that most isolates corresponded with facultative aerobic bacteria, which may demonstrate their high prevalence both in the bacterial communities present in women with CC and those without the pathology. According to Donders et al. (2017), one of the essential elements in aerobic vaginitis is colonization for Escherichia coli, Staphylococcus aureus, S. epidermidis, Streptococcus agalactiae, and Enterococcus faecalis. In our study, both groups presented bacteria typical of aerobic vaginitis. However, there were more strains isolated in women with cancer. This finding could contribute to the observation of Plisko et al. (Plisko et al., 2021), who concluded that changes in the microbiota associated with aerobic vaginitis are related to pre-invasive lesions. With our results, we can consider that these changes may also be related to cancer establishment.

Regarding the presence of this same group of bacteria in women without CC, although with lower strains isolated and fewer species, we can elucidate that this may represent infection or dysbiosis, but HPV infection is probably necessary for neoplastic changes to develop. According to Vieira-Baptista et al. (Vieira-Baptista et al., 2016), aerobic vaginitis is not associated with an increased risk of acquiring HPV, but it has been associated with the persistence of infection. It can therefore be considered a risk factor. The consequences of this and why it may or may not be related to the development of neoplasia should be studied under future designs and should also be studied considering the presence or not of HPV infection. These are two aspects that we did not consider in our study, representing points for improvement in subsequent projects.

Concerning the clinical stage of the disease, we found that more advanced stages presented a higher number of isolates and a more significant number of species coincident with aerobic vaginitis. On the contrary, less extended clinical stages showed a lower number of species and a more consistent bacterial community, with a better local ecology; this is consistent with previous studies (Audirac-Chalifour et al., 2016; García-García et al., 2017).

About the presence of these species and the severity of the disease, we know that aerobic vaginitis is an entity that by itself generates discomfort by producing a variable amount of inflammation and thinning of the vaginal epithelium 
(Oerlemans et al., 2020). We can elucidate that this dysbiotic microbiota could drive the pathology by promoting immune evasion, favoring tumor cell survival. It could also act by producing an inflammatory environment that in the long term promotes tissue damage resulting in an ecosystem more conducive to disease aggravation. These two aspects have been previously addressed to relate carcinogenesis to aerobic vaginosis, but not to explain the severity of the disease (VieiraBaptista et al., 2016; Donders et al., 2017; Plisko et al., 2021). We suggest studies whose aim is directed to the analysis of these variables.

No marked differences were observed in histological type for the microbiota associated with either of the two carcinomas found in this study group. In general, squamous cell carcinoma was related to a more significant bacterial presence, both in quantity and species number; this could be influenced by the anatomical characteristics of the tumor, which could provide a more favorable habitat for the installation of these species. A larger sample size regarding adenocarcinoma is likely to be necessary to obtain conclusive results.

Our study does not provide fundamentals to determine a causal association between the bacteria characteristic of aerobic vaginitis and cervicovaginal neoplasia; we do not have elements to clarify if aerobic vaginitis promotes carcinogenesis or if it is established as a consequence of cancer development due to the deprivation of the immune system when trying to counteract the neoplasia. But considering previous studies that have demonstrated a link between an altered vaginal microbiome and pre-invasive cervical disease, we propose that aerobic vaginitis and the inflammation with which it is accompanied are probably crucial for the progression of preneoplastic lesions to cancer (Vieira-Baptista et al., 2016; Plisko et al., 2021).

This cross-sectional study, developed as a preliminary experiment for further research, made it possible to explore the essential characteristics of the cervicovaginal microbiota associated with cervical cancer, the differences between women with and without the pathology, and the need for more in-depth studies. It also allowed us to establish variables for future analyses, funding needs, and sample collection and treatment methods.

Although the "omics" era has accelerated all aspects of biological research, it is advisable to integrate traditional microbiology methods to formulate optimal study designs. Conducting a research project depends primarily on the scientific objective and the availability of samples, the quality of the samples, and the cost of the experiment. Massive sequencing of $16 \mathrm{~S} r \mathrm{RNA}$ gene amplicons and metagenomic sequencing is used to obtain a broader view of bacterial communities and determine potential functions and genome recovery. However, it generally involves the development of large-scale research projects with sufficient funding. In developing countries, where financial resources in science and technology are scarce, it is essential to perform detailed designs that properly manage samples, variables, and financial resources, minimizing losses. Our preliminary identification of the microbiota as a preliminary approach to metagenomic studies can contribute to establishing this type of design.
We can conclude that we were able to establish the presence of bacteria typical of the entity known as aerobic vaginitis in women with CC and that it is crucial to carry out more in-depth studies. There is little information about this dysbiosis and its association with cervical cancer, so the reported findings are helpful to corroborate that there are bacterial communities that, although they may be abundant, so far have been little studied and whose influence on the establishment, development, or cure of CC are unknown. Our report shows that cross-sectional study designs and traditional microbiological methodology are helpful to determine whether there is a need for more complex studies and to know whether it is necessary to optimize the management of variables, samples, and financial resources.

Among the limitations of this study, we consider it necessary to report that we did not manage to extend the participants' last use of antimicrobials and antifungals, so we limited ourselves to 30 days as exclusion criteria. We know that this period is short for the microbiota to recover satisfactorily and return to "normal". However, we tried to lessen its impact by choosing a large sample size that balanced some of the participants' confounding results. Subsequent studies should address this issue. Likewise, we could not diagnose aerobic vaginitis or identify HPV; however, this is a precedent for future work to determine the association between aerobic vaginitis and HPV infection or persistence. Finally, we consider it a limitation to have performed a cross-sectional study. However, this is an antecedent for future studies to address longitudinal designs in which the relationship between aerobic vaginitis and cervical cancer can be evaluated more effectively.

\section{DATA AVAILABILITY STATEMENT}

The obtained sequences are publicly available in the GenBank of the National Center for Biotechnology Information with access numbers MH108987-MH109026 (Group 1) and MH158254MH158283 (Group 2). All other data in the study are available on request from the corresponding author.

\section{ETHICS STATEMENT}

The studies involving human participants were reviewed and approved by Ethics and Research Committee of the National Cancer Institute of Mexico (INCan, 016/11/ICI-CEI/1016). The patients/participants provided their written informed consent to participate in this study.

\section{AUTHOR CONTRIBUTIONS}

GM-L, JC-M, MR-M, LB-M, HS-T, and NR-D participated in the study design. JC-M, MR-M, and IR-C collected epidemiological data. GM-L, MR-M, and IR-C performed sample collection. GM-L, HS-T, and NR-D executed the experiment. GM-L and 
LB-M performed the analysis of results. All authors contributed to the article and approved the version presented.

\section{ACKNOWLEDGMENTS}

We acknowledge the support provided by the Consejo Mexiquense de Ciencia y Tecnología (COMECYT) through the

\section{REFERENCES}

Akinlotan, M., Bolin, J. N., Helduser, J., Ojinnaka, C., Lichorad, A., and McClellan, D. (2017). Cervical Cancer Screening Barriers and Risk Factor Knowledge Among Uninsured Women. J. Community Health 42, 770-778. doi: 10.1007/ s10900-017-0316-9

Altschul, S. F., Gish, W., Miller, W., Myers, E. W., and Lipman, D. J. (1990). Basic Local Alignment Search Tool. J. Mol. Biol. 215, 403-410. doi: 10.1016/S00222836(05)80360-2

Anahtar, M. N., Byrne, E. H., Doherty, K. E., Bowman, B. A., Yamamoto, H. S., Soumillon, M., et al. (2015). Cervicovaginal Bacteria are a Major Modulator of Host Inflammatory Responses in the Female Genital Tract. Immunity 42, 965976. doi: 10.1016/j.immuni.2015.04.019

Audirac-Chalifour, A., Torres-Poveda, K., Bahena-Román, M., Téllez-Sosa, J., Martínez-Barnetche, J., Cortina-Ceballos, B., et al. (2016). Cervical Microbiome and Cytokine Profile at Various Stages of Cervical Cancer: A Pilot Study. PLoS One 11, e0153274-e0153274. doi: 10.1371/journal.pone.0153274

Baezconde-Garbanati, L., Agurto, I., Gravitt, P. E., Luciani, S., Murphy, S., Ochoa, C., et al. (2019). Barriers and Innovative Interventions for Early Detection of Cervical Cancer. Salud Publica Mex. 61, 456-460. doi: 10.21149/10425

Bray, F., Ferlay, J., Soerjomataram, I., Siegel, R. L., Torre, L. A., and Jemal, A. (2018). Global Cancer Statistics 2018: GLOBOCAN Estimates of Incidence and Mortality Worldwide for 36 Cancers in 185 Countries. CA. Cancer J. Clin. 68, 394-424. doi: 10.3322/caac. 21492

Brusselaers, N., Shrestha, S., van de Wijgert, J., and Verstraelen, H. (2019). Vaginal Dysbiosis and the Risk of Human Papillomavirus and Cervical Cancer: Systematic Review and Meta-Analysis. Am. J. Obstet. Gynecol. 221, 9-18.e8. doi: 10.1016/j.ajog.2018.12.011

Chen, H.-Y., Kessler, C. L., Mori, N., and Chauhan, S. P. (2012). Cervical Cancer Screening in the United State-2010: Characteristics of Women Who are Never Screened. J. women's Heal. 21, 1132-1138. doi: 10.1089/jwh.2011.3418

Creatsas, G., and Deligeoroglou, E. (2012). Microbial Ecology of the Lower Genital Tract in Women With Sexually Transmitted Diseases. J. Med. Microbiol. 61, 1347-1351. doi: 10.1099/jmm.0.042507-0

Dahiya, N., Bachani, D., Acharya, A. S., Sharma, D. N., Gupta, S., and Haresh, K. P. (2017). Socio-Demographic, Reproductive and Clinical Profile of Women Diagnosed With Advanced Cervical Cancer in a Tertiary Care Institute of Delhi. J. Obstet. Gynaecol. India 67, 53-60. doi: 10.1007/s13224-016-0907-x

Di Paola, M., Sani, C., Clemente, A. M., Iossa, A., Perissi, E., Castronovo, G., et al. (2017). Characterization of Cervico-Vaginal Microbiota in Women Developing Persistent High-Risk Human Papillomavirus Infection. Sci. Rep. 7, 10200. doi: 10.1038/s41598-017-09842-6

Donders, G. G. G., Bellen, G., Grinceviciene, S., Ruban, K., and Vieira-Baptista, P. (2017). Aerobic Vaginitis: No Longer a Stranger. Res. Microbiol. 168, 845-858. doi: 10.1016/j.resmic.2017.04.004

Donders, G. G. G., Vereecken, A., Bosmans, E., Dekeersmaecker, A., Salembier, G., and Spitz, B. (2002). Definition of a Type of Abnormal Vaginal Flora That is Distinct From Bacterial Vaginosis: Aerobic Vaginitis. BJOG 109, 34-43. doi: 10.1111/j.1471-0528.2002.00432.x

Gao, W., Weng, J., Gao, Y., and Chen, X. (2013). Comparison of the Vaginal Microbiota Diversity of Women With and Without Human Papillomavirus Infection: A Cross-Sectional Study. BMC Infect. Dis. 13, 271. doi: 10.1186/ 1471-2334-13-271

García-García, A., Coronel-Martínez, J., Leon, D. C., Romero-Figueroa, M. D. S., Caballero-Pantoja, Y. E., Manzanares-Leal, G. L., et al. (2017). Detection of Actinomyces Spp. In Cervical Exudates From Women With Cervical program "Cátedras COMECYT EDOMEX”, folio CAT2021-0106.

The authors are grateful for the financial support of the Secretaría de Investigación y Estudios Avanzados de la Universidad Autónoma del Estado de México through the research project, "Estudio metagenómico del microbioma cervicovaginal presente en mujeres con cáncer cervicouterino y bajo tratamientos antineoplásicos" 6387/2021ESP.

Intraepithelial Neoplasia or Cervical Cancer. J. Med. Microbiol. 66, 706-712. doi: 10.1099/jmm.0.000485

Gillet, E., Meys, J. F. A., Verstraelen, H., Verhelst, R., De Sutter, P., Temmerman, M., et al. (2012). Association Between Bacterial Vaginosis and Cervical Intraepithelial Neoplasia: Systematic Review and Meta-Analysis. PLoS One 7, e45201. doi: 10.1371/journal.pone.0045201

Hall, T. A. (1999). BioEdit : A User-Friendly Biological Sequence Alignment Editor and Analysis Program for Windows 95/98/Nt. Nucleic Acids Symp. Ser. 41, 95-98.

Huang, Y., Wu, X., Lin, Y., Li, W., Liu, J., and Song, B. (2020). Multiple Sexual Partners and Vaginal Microecological Disorder are Associated With HPV Infection and Cervical Carcinoma Development. Oncol. Lett. 20, 1915-1921. doi: $10.3892 / \mathrm{ol} .2020 .11738$

Ilhan, Z. E., Łaniewski, P., Thomas, N., Roe, D. J., Chase, D. M., and HerbstKralovetz, M. M. (2019). Deciphering the Complex Interplay Between Microbiota, HPV, Inflammation and Cancer Through Cervicovaginal Metabolic Profiling. EBioMedicine 44, 675-690. doi: 10.1016/j.ebiom. 2019.04.028

Jørgensen, H., Fjaervik, E., Hakvåg, S., Bruheim, P., Bredholt, H., Klinkenberg, G., et al. (2009). Candicidin Biosynthesis Gene Cluster is Widely Distributed Among Streptomyces Spp. Isolated From the Sediments and the Neuston Layer of the Trondheim Fjord, Norway. Appl. Environ. Microbiol. 75, 3296-3303. doi: 10.1128/AEM.02730-08

Kang, G.-U., Jung, D.-R., Lee, Y. H., Jeon, S. Y., Han, H. S., Chong, G. O., et al. (2021). Potential Association Between Vaginal Microbiota and Cervical Carcinogenesis in Korean Women: A Cohort Study. Microorganisms 9, 294. doi: 10.3390/microorganisms 9020294

Kovachev, S. M. (2020). Cervical Cancer and Vaginal Microbiota Changes. Arch. Microbiol. 202, 323-327. doi: 10.1007/s00203-019-01747-4

Kroon, S. J., Ravel, J., and Huston, W. M. (2018). Cervicovaginal Microbiota, Women's Health, and Reproductive Outcomes. Fertil. Steril. 110, 327-336. doi: 10.1016/j.fertnstert.2018.06.036

Kwasniewski, W., Wolun-Cholewa, M., Kotarski, J., Warchol, W., Kuzma, D., Kwasniewska, A., et al. (2018). Microbiota Dysbiosis is Associated With HPVInduced Cervical Carcinogenesis. Oncol. Lett. 16, 7035-7047. doi: 10.3892/ ol.2018.9509

Łaniewski, P., Barnes, D., Goulder, A., Cui, H., Roe, D. J., Chase, D. M., et al. (2018). Linking Cervicovaginal Immune Signatures, HPV and Microbiota Composition in Cervical Carcinogenesis in Non-Hispanic and Hispanic Women. Sci. Rep. 8, 7593. doi: 10.1038/s41598-018-25879-7

Martínez-Peña, M. D., Castro-Escarpulli, G., and Aguilera-Arreola, M. G. (2013). Lactobacillus Species Isolated From Vaginal Secretions of Healthy and Bacterial Vaginosis-Intermediate Mexican Women: A Prospective Study. BMC Infect. Dis. 13, 189. doi: 10.1186/1471-2334-13-189

Martínez-Rodríguez, F., Limones-González, J. E., Mendoza-Almanza, B., EsparzaIbarra, E. L., Gallegos-Flores, P. I., Ayala-Luján, J. L., et al. (2021) Understanding Cervical Cancer Through Proteomics. Cells 10, 1854. doi: 10.3390/cells10081854

Mitra, A., MacIntyre, D. A., Lee, Y. S., Smith, A., Marchesi, J. R., Lehne, B., et al. (2015). Cervical Intraepithelial Neoplasia Disease Progression is Associated With Increased Vaginal Microbiome Diversity. Sci. Rep. 5, 16865. doi: 10.1038/ srep 16865

Nessa, A., Ara, R., Fatema, P., Nasrin, B., Chowdhury, A., Khan, K. H., et al. (2020). Influence of Demographic and Reproductive Factors on Cervical PreCancer and Cancer in Bangladesh. Asian Pac. J. Cancer Prev. 21, 1883-1889. doi: 10.31557/APJCP.2020.21.7.1883 
Norenhag, J., Du, J., Olovsson, M., Verstraelen, H., Engstrand, L., and Brusselaers, N. (2020). The Vaginal Microbiota, Human Papillomavirus and Cervical Dysplasia: A Systematic Review and Network Meta-Analysis. BJOG Int. J. Obstet. Gynaecol. 127, 171-180. doi: 10.1111/1471-0528.15854

Oerlemans, E. F. M., Wuyts, S., Bellen, G., Wittouck, S., De Boeck, I., Ruban, K., et al. (2020). The Dwindling Microbiota of Aerobic Vaginitis, an Inflammatory State Enriched in Pathobionts With Limited TLR Stimulation. Diagnostics 10, 879. doi: 10.3390/diagnostics10110879

Onywera, H., Anejo-Okopi, J., Mwapagha, L. M., Okendo, J., and Williamson, A.L. (2021). Predictive Functional Analysis Reveals Inferred Features Unique to Cervicovaginal Microbiota of African Women With Bacterial Vaginosis and High-Risk Human Papillomavirus Infection. PLoS One 16, e0253218. doi: 10.1371/journal.pone.0253218

Piyathilake, C. J., Ollberding, N. J., Kumar, R., Macaluso, M., Alvarez, R. D., and Morrow, C. D. (2016). Cervical Microbiota Associated With Higher Grade Cervical Intraepithelial Neoplasia in Women Infected With High-Risk Human Papillomaviruses. Cancer Prev. Res. (Phila). 9, 357-366. doi: 10.1158/19406207.CAPR-15-0350

Plisko, O., Zodzika, J., Jermakova, I., Pcolkina, K., Prusakevica, A., LiepnieceKarele, I., et al. (2021). Aerobic Vaginitis-Underestimated Risk Factor for Cervical Intraepithelial Neoplasia. Diagnostics 11, 97. doi: 10.3390/ diagnostics 11010097

Ravel, J., Gajer, P., Abdo, Z., Schneider, G. M., Koenig, S. S. K., McCulle, S. L., et al. (2011). Vaginal Microbiome of Reproductive-Age Women. Proc. Natl. Acad. Sci. 108, 4680 LP - 4687. doi: 10.1073/pnas.1002611107

Saleh, M., Virarkar, M., Javadi, S., Elsherif, S. B., de Castro Faria, S., and Bhosale, P. (2020). Cervical Cancer: 2018 Revised International Federation of Gynecology and Obstetrics Staging System and the Role of Imaging. AJR. Am. J. Roentgenol. 214, 1182-1195. doi: 10.2214/AJR.19.21819

Sodhani, P., Gupta, S., Gupta, R., and Mehrotra, R. (2017). Bacterial Vaginosis and Cervical Intraepithelial Neoplasia: Is There an Association or Is Co-Existence Incidental? Asian Pac. J. Cancer Prev. 18, 1289-1292. doi: 10.22034/ APJCP.2017.18.5.1289

Thulaseedharan, J. V., Malila, N., Hakama, M., Esmy, P. O., Cheriyan, M., Swaminathan, R., et al. (2012). Socio Demographic and Reproductive Risk Factors for Cervical Cancer - A Large Prospective Cohort Study From Rural India. Asian Pac. J. Cancer Prev. 13, 2991-2995. doi: 10.7314/apjcp. 2012.13.6.2991
Usyk, M., Zolnik, C. P., Castle, P. E., Porras, C., Herrero, R., Gradissimo, A., et al. (2020). Cervicovaginal Microbiome and Natural History of HPV in a Longitudinal Study. PLoS Pathog. 16, e1008376. doi: 10.1371/journal.ppat. 1008376

Vieira-Baptista, P., Lima-Silva, J., Pinto, C., Saldanha, C., Beires, J., Martinez-deOliveira, J., et al. (2016). Bacterial Vaginosis, Aerobic Vaginitis, Vaginal Inflammation and Major Pap Smear Abnormalities. Eur. J. Clin. Microbiol. Infect. Dis. 35, 657-664. doi: 10.1007/s10096-016-2584-1

Wang, C., Fan, A., Li, H., Yan, Y., Qi, W., Wang, Y., et al. (2020). Vaginal Bacterial Profiles of Aerobic Vaginitis: A Case-Control Study. Diagn. Microbiol. Infect. Dis. 96, 114981. doi: 10.1016/j.diagmicrobio.2019.114981

Wei, Z.-T., Chen, H.-L., Wang, C.-F., Yang, G.-L., Han, S.-M., and Zhang, S.-L. (2020). Depiction of Vaginal Microbiota in Women With High-Risk Human Papillomavirus Infection. Front. Public Heal. 8. doi: 10.3389/fpubh.2020. 587298

Yoon, S.-H., Ha, S.-M., Kwon, S., Lim, J., Kim, Y., Seo, H., et al. (2017). Introducing EzBioCloud: A Taxonomically United Database of $16 \mathrm{~S}$ rRNA Gene Sequences and Whole-Genome Assemblies. Int. J. Syst. Evol. Microbiol. 67, 1613-1617. doi: 10.1099/ijsem.0.001755

Conflict of Interest: The authors declare that the research was conducted in the absence of any commercial or financial relationships that could be construed as a potential conflict of interest.

Publisher's Note: All claims expressed in this article are solely those of the authors and do not necessarily represent those of their affiliated organizations, or those of the publisher, the editors and the reviewers. Any product that may be evaluated in this article, or claim that may be made by its manufacturer, is not guaranteed or endorsed by the publisher.

Copyright (C) 2022 Manzanares-Leal, Coronel-Martínez, Rodríguez-Morales, Rangel-Cuevas, Bustamante-Montes, Sandoval-Trujillo and Ramírez-Durán. This is an open-access article distributed under the terms of the Creative Commons Attribution License (CC BY). The use, distribution or reproduction in other forums is permitted, provided the original author(s) and the copyright owner(s) are credited and that the original publication in this journal is cited, in accordance with accepted academic practice. No use, distribution or reproduction is permitted which does not comply with these terms. 